\title{
Review of Building Teaching and Learning Communities: Creating Shared Meaning and Purpose
}

Cristy Moran

Broward College

Abstract: Review of Gibson, C. \& Mader, S. (Eds.) (2019). Building teaching and learning communities:

Creating shared meaning and purpose. Association of College and Research Libraries.

Keywords: academic libraries, higher education, faculty, collaboration, learning communities, teaching, pedagogy, information literacy

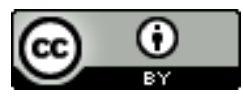

This is an Open Access article distributed under the terms of the Creative Commons Attribution 4.0 International License (http://creativecommons.org/licenses/by/4.0), which permits unrestricted use, distribution, and reproduction in any medium, provided the original work is properly cited. 
What place the librarian occupies and how to occupy the place the librarian wants to occupy has been the source of much writing. Mader and Gibson's Building Teaching and Learning Communities: Creating Shared Meaning and Purpose answers those questions through the lens of the ACRL's Roles and Strengths of Teaching Librarians document. Emphasized throughout various roles are collaboration, contextualization, and integration. Implicit is the idea that information literacy transcends the library domain. The academic librarian, the Roles and Strengths suggest, is a part of the broader institution and/or campus community. Beginning broadly with Hutchings and Socrinelli's examination of the trend toward pedagogical excellence at the institution level, the volume moves to the use of Scholarship of Teaching and Learning (SoTL) as a worthwhile effort toward that goal in Hodges' essay in the second chapter, and then to Chick's connecting signature pedagogies and SoTL to academic librarian practice in the third chapter. The six essays collected in this book progress toward the librarian's place in the academic institution, as educators and members of their college's or university's community of educators. While some essays remain broad, others drill down with examples of collaborations or projects that readers can use as guidance for their own practices.

Challenges arise throughout the collection, too. Faculty-librarian collaborations and the endeavor of learning pedagogy are likened to the Framework's threshold concepts with descriptions like "troublesome" and "liminal" used throughout. An undercurrent throughout Building Teaching and Learning Communities is a reminder that it's not easy-even when it works. For librarians struggling to make inroads with other departments in highly siloed institutions, these are refreshing and validating observations. Reflecting on the work of faculty-librarian collaboration and on engaging in teaching and learning communities, the essays regularly return to the Framework, utilizing it a meta-document that speaks both to the student of information literacy and to the teachers of it. 
Hutchings and Sorcinelli present Austin's Framework for Change, focusing on the role of librarians as agents with a rare position at the intersections of the model's four levers of institutional change: professional development, resources, incentives and rewards, and leadership. Their short chapter defines the framework and adeptly illustrates how its "both flexible (allowing for approaches to culture change that alight with different institutional cultures) and broad (covering a wide range of stakeholder groups, roles, and functions)" nature is in keeping with the roles that many of us employ in our colleges and universities (p. 19). As much as it is a description of the framework, Hutchings and Sorcinelli's chapter calls librarians to action. Rather than presenting a manual for outreach to individual faculty or academic departments, they present real-life examples of librarians working with their institutions' centers of teaching and learning (traditionally professional development), learning communities, and Scholarship of Teaching and Learning, leveraging the library's benefit of multidisciplinary positioning to support and engage our institutions' shifts toward more learningfocused environments.

In the next chapter, Hodges examines SoTL-a particularly useful essay for readers unfamiliar with it. The case for SoTL is formulated around the faulty assumption that expert knowledge in a field or content area equates to the ability to teach that subject. Rather, in becoming experts, faculty have more than forgotten how to become learners; they have become unable to connect with the experience of learning, having developed "expert blind spots" (p. 30). This creates a misalignment between their expectations of students and the reality of their students' abilities. SoTL is an opportunity for faculty to both learn how to become educators and to reconnect to the experience of learning. Engaging in a learning community like SoTL where the expert (faculty member) reverts to a novice state (specifically around pedagogy) akin to that of their student is itself a "troublesome" 
experience both intellectually and emotionally, but one that Hodges describes as a "sustaining" and supportive environment in both regards (p. 30).

SoTL is a burgeoning field of interest in higher education. In so far as the theme of this volume-building teaching and learning communities-SoTL can function as a theme around which a community of practice is organized. Though Hodges touches on this toward the end of her chapter, she primarily writes to champion the pursuit of SoTL rather than as a guide or model on how to organize a community of SoTL scholars. In her efforts, she is successful, particularly in defining pedagogy as threshold concepts often unknown or avoided by faculty. Hodges' essay provides a broader view of SoTL in chapter two, that is narrowed to a more precise view through the librarian lens in Chick's subsequent chapter, exploring signature pedagogies. Together, these chapters are instructive for the self-reflective teacher librarian, guiding one on how to begin with traditional concepts of librarianship to connect to other disciplines-a direct response to the Framework's integrative and multidisciplinary call.

For librarians relegated to one-shot instruction, it can be difficult to envision oneself as a candidate for SoTL. All the more welcome, then, are Chick's use of common library classroom activities and assessments like the minute paper and the muddiest point as well as lesser known ones like thinkalouds as examples of potential points of inquiry for SoTL librarians (p. 44-46). Signature pedagogy is a less familiar term for librarians (and likely to the higher education community at-large), yet it presents an attractive challenge: to discover the signature pedagogy of librarians. When Chick challenges the reader to consider if the teaching librarian's context and environment lend themselves to a unique signature pedagogy that can inform our colleagues to whom it is otherwise invisible (p. 46). 
Middendorf and Baer narrow the focus on information literacy pedagogy, specifically exploring information literacy through the Decoding the Disciplines model, developed by co-author Joan Middendorf and historian David Pace (not a contributor to the article). The chapter presents Middendorf's and Baer's study of librarian perceptions of "bottlenecks" (or areas where people "get stuck" along a process) in information literacy learning and teaching; and it further serves as an example of the collaborations that the other chapters encourage. Middendorf and Baer work across disciplines-Baer is an instructional librarian and Middendorf is an educational developer-to investigate information literacy pedagogy, turning Decoding the Disciplines to the experience of the instructional librarian.

Much of the chapter is spent breaking down information literacy pedagogy through the Decoding the Disciplines model and addressing the findings (p. 56-63). However, the authors return to the theme of community and collaboration, writing that the model "provides a theoretical framework that can be used when leading learning communities" (p. 63). Leveraging the library's naturally multidisciplinary position at the institutions to lead recalls Hutchings and Sorcinelli's earlier chapter. If, as Hodges and Sorcinelli suggest, the intersections of the disciplines-the academic librarian's home base-provides a vantage point from where librarians can lead to support faculty through "decoding" their disciplines.

Felten et al. begin their chapter by acknowledging the challenges of collaboration with which many academic librarians are familiar: the hierarchies inherent in academia, the siloed nature of institutions which often limit access to people in other areas and disciplines, and the difficulty of gaining buy-in from both faculty andstudents for teaching that challenges the norms or the familiar. Unique among the essays in Building Teaching and Learning Communities, Felten et al. include 
students among the pedagogical partners. After describing two examples of pedagogical interventions that involve collaboration between faculty and student partners-Students as Learners and Teachers at Bryn Mawr and Haverford Colleges and the Course Design Team at Elon University, the authors present a case study (also at Elon University) of a triad collaboration between a librarian, discipline faculty member, and student (p. 72). The authors detail the long lens of the faculty-librarian relationship, from the challenges of a new faculty member to conflicting expectations. The student partner's role is comparably underwritten; however, the inclusion of a student in collaborations remains instructive to librarians who hadn't considered students a potential partner.

Schray's chapter, the final of the six contributed essays, epitomizes the value of intentional, formalized, and systemic teaching and learning communities, collaborations, and efforts described in the preceding chapters. Marshall University's Writing across the Curriculum (WAC) program, Schray writes, "demonstrates the ultimate potential of what can happen when a group of committed faculty come together to talk about becoming better teachers" (p. 82). What grew from faculty inquiry about student learning in the 1990's has developed into a formal and "official" community of practice. From its inception, Marshall's WAC community has been multidisciplinary and faculty-driven. Once institution-level support was secured, formal learning opportunities and professional development were provided, and the community grew. The impact of WAC continues with a dedicated office based out of the university's Center of Teaching and Learning and goes beyond writing-focused pedagogy as other faculty learning communities (FLCS) with varying interests have formed.

The types and benefits of FLCs at Marshall are evidenced in detail, as is the value of librarians to them. Schray is not a librarian. Through working in FLCs with a librarian, Schray came to value the "obvious step" of inviting librarians to participate in FLCs. "Many of our FLC participants acknowledged 
that they did not realize the extent to which librarians can assist them in their professional lives" ( $p$. 92). Information literacy, the Framework, and the unique space the librarian occupies in the academic institution are benefits to the pedagogical development of faculty, whether they realize it at the time or not. Schray reasserts what the previous authors have claimed in their contributions: librarians belong in teaching and learning communities.

The academic librarianship described in Building Teaching and Learning Communities is defined in the Roles and Strengths of Teaching Librarians. Readers who want to learn more will be grateful for the extensive notes and bibliographies provided for each essay. For librarians new to academic libraries or for librarians whose institutions are transitioning to "centers of teaching and learning" for their professional development departments, this collection acts as a primer on higher education trends like SoTL, signature pedagogies, Decoding the Disciplines, WAC, learning communities, and faculty-librarian collaboration based on teaching. Though much of this collection speaks to collaborations with faculty outside the library, it can also be effective as a conversationstarter among a team of college or university librarians who are asking important questions about their roles and the roles of their profession in this burgeoning climate. Though often collections like this can be picked through, read in part or chapters read in random order, the recommend reading order is as arranged, start-to-finish, as its themes unfurl through the progression of essays, first proposing a framework, then identifying trends in higher education, and finally centering on the librarian with examples of collaborations and guidance to that end. 